\title{
For whom the bells knell
}

\author{
Bryan Jennett Institute of Neurological Sciences, Glasgow
}

Decisions to limit treatment are frequently discussed in the abstract, at meetings or in journals (1). They are less often considered by clinicians in their normal practice, as far as is known. For various reasons statistics about such events do not usually reach the medical literature although individual examples are quoted to illustrate ethical principles or dilemmas. Such is the case described so vividly by Doctors Heim and Steinbach.

It can be summarised in a way that emphasises the decisions that were made and their consequences. At the age of 68 this widow suffered a fractured neck of femur and she regained her independence after surgery. However, by the time she broke the other hip three years later she had been becoming progressively demented over the previous six months, and the degree of dementia was such that it was decided to withhold surgery. She never walked again but remained dependent and bed-ridden in institutions; she developed an adduction contracture of the hip and extensive multiple bed sores whilst her dementia progressed. However, it seems that her transfer from the nursing home to the emergency room of an acute hospital had mainly been precipitated by her having become unresponsive in the last 24 hours. She had gangrene of the left leg but it is unclear for how long this had been developing or whether it had been painful.

On arrival at the acute hospital she was in coma, responding only to painful stimuli. She had pressure sores on both trochanteric areas and an enormous sacral sore; the extent of the limb gangrene is not mentioned but there was a terrible smell and worm infestation of the necrotic sores. Haemoglobin was $8.6 \mathrm{~g}$ and temperature $39^{\circ} \mathrm{C}$. After blood transfusion and correction of electrolyte balance she regained consciousness - to her previous disoriented and demented state, although she was able to recognise her son who had been summoned to her bedside. Two weeks later an amputation of the leg was carried out and one of the three bed sores was sutured. She spent three more weeks in the acute hospital and lived for two

\section{Key words}

Incompetent patients. further weeks after being returned to the nursing home. It could be said that she had spent seven weeks of active and expensive treatment in the process of dying.

There is more to this case, from an ethical viewpoint, than the question of whether or not she should have had surgery in her terminal illness. When she presented in coma at the age of 72 , this was already one year after a previous decision had been made to withhold surgery for her fractured hip because she had already become so demented. What possible benefit could come from correcting the physiological abnormalities that had mercifully produced coma and which, if treatment had been withheld, would soon have led to her death? If a non-treatment decision had already been made on the basis of dementia, a condition that was now worse, would logic not demand that coma also not be treated? Given the intractable nature of her bedsores and gangrene could the development of coma not have been regarded as the beginning of a good death?

Once the doctors had yielded to the temptation to treat the acute situation reflexly and routinely, without due consideration of the case as a whole, a cycle of commitment had begun. It then became difficult to resist the surgical imperative to amputate, although why this was delayed for two weeks is unclear. If the only source of gangrene and of offensive tissue had been the lower leg there might have been some justification in amputation, given that she had already been inadvisedly 'rescued' from coma. But it seems that there was no prospect of closing the huge sacral sore and therefore of dealing with its smell (and perhaps pain). If that was so, what good purpose was served by the amputation?

\section{General discussion}

Most discussion has centred on the circumstances that justify the decision not to apply cardiopulmonary resuscitation (DNR orders). It has recently been suggested that clear distinctions should be made between the reasons for withholding CPR (2). Three are proposed: that CPR would be futile because it is very unlikely to be successful; that quality of life after CPR is likely to be changed to so poor a level as to be a greater burden than the benefit gained from 
prolongation of life, and that quality of life is already so poor due to chronic or terminal disease that life should not be prolonged by CPR. That critique pointed out that when DNR orders are based on the last reason then the same logic would support the withholding of other life-prolonging measures.

The reason why CPR attracts attention, and appears to demand a prior directive, is because of the need to make a rapid decision when cardiorespiratory arrest occurs, a decision that must often be made by junior medical or by nursing staff. Other measures often considered as life-prolonging or life-supporting are sometimes classified as basic or advanced, as in a recent review of the use of such measures in adults (3). This stated that 'comatose hopelessly ill people may be pulled back needlessly from a painless death to live out an extra few days or weeks in pain and indignity'. And later it commented, 'once an IV line is in place it is harder to refrain from treating infections and chemical imbalances that might provide a humane release'.

There is a wide range of interventions that may be withheld and rather than two categories it is helpful to recognise a third - which may be called normal treatment or rescue. In the effort to relieve suffering it may be necessary to initiate a limited amount of palliative, active treatment designed to control disease processes or physiological abnormalities; for example, surgical removal of a painful limb, or radiotherapy for a mediastinal mass that is causing acute respiratory distress or for painful bone metastases. This palliative treatment may prolong life, but this is a by-product of relieving symptoms, not its primary purpose. This is the opposite of the effect of analgesic drugs that may shorten life as a by-product of relieving symptoms.

Surgery is one type of normal treatment. Inappropriate surgery for patients who have advanced disease, and/or who are elderly, may be more common than is realised. The confidential enquiry of deaths within 30 days of operation in three English regions found that 79 per cent of more than 4,000 cases investigated were over the age of 65 , an age group that accounts for only 22 per cent of all operations performed; 70 per cent of the deaths were in patients over 70 years $(4,5)$. In most cases death was due to the advanced stage either of the primary disease for which surgery was undertaken or of co-existing disease in other systems. It seems that many of these elderly patients with advanced disease died in spite of surgery rather than because of it, although the intervention may have accelerated their death in some instances. Many of these patients had been operated on as emergencies, often in the hands of inexperienced surgeons and anaesthetists. On review it was considered that in many instances a decision could have been postponed until there had been more time for balancing the probable risks and possible benefits, and for more senior clinicians to be consulted.

It is, however, important to realise that many elderly patients can benefit greatly from surgical procedures (for example hip replacement, cataract removal, prostatectomy). It is therefore important not to deny elderly patients the chance of improvement in their quality of life from surgery on the grounds of age alone (6). But if a patient is already disabled from progressive disease in other systems (in particular the brain), then the appropriateness of surgery should be carefully considered. This is particularly important when a patient presents as an emergency, because decisions are then apt to be made without sufficient consultation between experienced colleagues or with the patient and the family. Even healthy old people have an increased risk from surgery and anaesthesia and if complications do develop they are less likely to respond well to intensive therapy (7). If a decision is made to give an elderly patient the chance of benefiting from surgery it may be wise to decide in advance that, if serious complications do develop, there will not be a commitment to a long period of futile intensive care.

Bryan fennett MD FRCS is Professor of Neurosurgery i the Institute of Neurological Sciences, Glasgow ariat Consultant Policy Adviser, King's Fund Institute, London.

\section{References}

(1) Jennett B. Decisions to limit treatment. Lancet 1987; ii: 787-789.

(2) Tomlinson T, Brodie H. Ethics and communication in do-not-resuscitate orders. New England journal of medicine 1988; 318: 43-46.

(3) Ruark J E, Raffin T A. The Stanford University Medical Center Committee on Ethics. New England journal of medicine 1988; 318: 25-30.

(4) Anonymous. [editorial] Accounting for perioperative deaths. Lancet 1987; ii: 1369-71.

(5) Lunn J N, Devlin J B. Lessons from the confidential enquiry into perioperative deaths in three NHS regions. Lancet 1987; ii: 1384-1386.

(6) Jennett B. High technology medicine and the elderly in o Britain. International journal of technical assessment in $N$ health care 1987; 3: 491-493.

(7) Jennett B. Intensive care for the elderly. International journal of technical assessment in health care 1985;1:7-19. 